Peer review: This article has been subject to a double blind peer review process

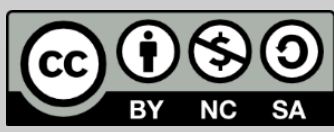

C Copyright: The Authors. This article is issued under the terms of the Creative Commons Attribution NonCommercial Share Alike License, which permits use and redistribution of the work provided that the original author and source are credited, the work is not used for commercial purposes and that any derivative works are made available under the same license terms.

\section{Memory Studies Goes Planetary: An Interview with Stef Craps}

\author{
Maria Roca Lizarazu and Rebekah Vince \\ University of Warwick \\ Correspondence: M-D.Roca-Lizarazu@warwick.ac.uk \& \\ R.L.Vince@warwick.ac.uk
}

\begin{abstract}
Stef Craps is Associate Professor of English Literature at Ghent University, where he directs the Cultural Memory Studies Initiative (CMSI). He is an internationally recognised scholar whose research focuses on postcolonial literatures, trauma theory, transcultural Holocaust memory, and, more recently, climate change fiction. He has published widely on these issues, including in the seminal Postcolonial Witnessing: Trauma Out of Bounds (Palgrave Macmillan, 2013). He visited Warwick to deliver a public lecture and graduate workshop for the Warwick Memory Group in October 2017. In a wide-ranging interview, Stef Craps spoke about present and future directions in memory and trauma studies, the differences between transnational and transcultural memories, the ethics and politics of memory (studies), and the challenges faced by the field looking to the future.
\end{abstract}

Keywords: memory studies; trauma studies; Holocaust memory; transnational and transcultural memory; climate change; digital memories

\section{Introduction}

Whither memory studies? This question has been asked countless times since the advent of memory studies as an academic field in the 1980s-do we need to ask it again? Arguably, the field has arrived at an important juncture in recent years: the 'memory boom' of the 1990s and 2000s has paved the way for an unprecedented consolidation, exemplified by numerous memory-themed conferences, publications, research centres, and associations. At the same time, memory studies is confronted with significant changes which will potentially recalibrate the field. These include the end of living memories of the Holocaust, the large-scale digitisation of memory, and a shift in focus 'from the transnational, transcultural, or global to the planetary, from recorded to deep history, and from the human to the nonhuman' (see p.13). 
We thus decided to take the opportunity to discuss present and future directions of memory studies, and their connection to contemporary political debates and broader socio-technological shifts, with Prof Stef Craps during his visit to the University of Warwick on 24th October 2017. He delivered a lecture and a graduate workshop for the Warwick Memory Group. His lecture 'Bearing Witness to the Anthropocene' explored recent cultural representations of climate change, while the graduate workshop engaged with postcolonial trauma theory and transcultural memories of the Holocaust.

Stef Craps is Associate Professor of English Literature at Ghent University, where he directs the Cultural Memory Studies Initiative (CMSI). He is an internationally recognised expert in the field, specialising in postcolonial literatures, trauma studies, transcultural Holocaust memory, and, more recently, climate change fiction or 'cli-fi'. He has published widely on these issues, including in the seminal Postcolonial Witnessing: Trauma Out of Bounds (Palgrave Macmillan, 2013). Together with Lucy Bond and Pieter Vermeulen, he recently edited Memory Unbound: Tracing the Dynamics of Memory Studies (Berghahn, 2017). He has also guest-edited special issues of Criticism: A Quarterly for Literature and the Arts (with Michael Rothberg, 2011) and Studies in the Novel (with Gert Buelens, 2008).

The Warwick Memory Group, organised by Prof Mark Philp (History) and Dr Maria Roca Lizarazu (IAS/SMLC), is an interdisciplinary group of graduate students and faculty with research interests in memory and memorialisation. The group aims to meet termly with sessions involving discussion of published (both recent and older) and unpublished work alongside formal presentations from experts in the field. The group also organises the Annual Memory Lecture and Master Class, which brings renowned experts in the field to the University of Warwick to talk about their most recent research. Guests include Astrid Erll (2014/15), Aleida Assmann (2015/16), Ann Rigney (2016/17), and Andrew Hoskins (2017/18).

\section{New Directions in Trauma Studies}

Maria Roca Lizarazu: How do you think the field of trauma studies has changed? I would argue there has been a shift since the turn of the millennium. Do you see that as well? What are important changes in the field of trauma studies at the moment?

Stef Craps: Around the turn of the century, there was a sense that trauma studies had stagnated somewhat. It's not as if nothing was happening, but I wasn't seeing much in terms of theoretical breakthroughs or conceptual innovation. I would say that over the last decade or so, there have been various signs of renewal and continuing relevance for the field. There have 
been quite a few people in recent years who have questioned the tenets laid down by the founders of the field in the mid-1990s, including Cathy Caruth, Shoshana Felman, Dori Laub, and Dominick LaCapra. As a result, the field is becoming a lot more flexible and pluralistic. Pluralisation and diversification are quite noticeable trends in trauma studies over the last five to ten years.

To begin with, there is a tendency to see trauma not just as a Western phenomenon but as a global one. I actually think that's a trend that is firmly established by now, though at the same time we're only at the beginning of that process. That's also where I would situate my own contribution to trauma studies. Looking back on my work in this areamostly my book Postcolonial Witnessing and a few articles that preceded and followed it (Craps, 2013)-with the benefit of a couple of years' hindsight, it has occurred to me that I tend to focus on literary texts that are written by postcolonial writers, yes, but writers who are based in the West, who address a Western audience, and who are steeped in Western culture. They are often more concerned with critiquing Western ideas and the injustice and inappropriateness of imposing Western frameworks on postcolonial contexts than with laying out concrete alternatives. Once the critique is out of the way, as it were, we can start studying beliefs about suffering and recovery and the media and forms of expression that are used to bear witness to trauma in specific local contexts, unencumbered by the burden of this canonical Western trauma theory. I think that's the next step, and while some scholars have already started doing just that kind of work in recent years, it seems to me that we still have a long way to go.

Another, related tendency is to move beyond trauma aesthetics, by which I mean the idea that the only appropriate way to write about trauma is through the use of experimental, avant-garde textual strategies, such as can be found in high-brow modernist and postmodern art. The move beyond normative trauma aesthetics and towards an appreciation of realism and popular-cultural genres as equally valid modes of bearing witness to trauma was spearheaded by Roger Luckhurst in The Trauma Question (Luckhurst, 2008). There have been several other people who have elaborated on that critique since then, most notably perhaps Alan Gibbs. In Contemporary American Trauma Narratives, he drives a cart and horses through many trauma-theoretical orthodoxies, including this formalist axiom and the aesthetic elitism that goes hand in hand with it (Gibbs, 2014).

Thirdly, there is a clear shift or broadening of focus from victim to perpetrator trauma. The notion of perpetrator trauma is still controversial, though, because of the habitual conflation of trauma and victimhood. The 
former is a clinical category; the latter a moral and legal one. However, as soon as you start talking about perpetrators who might have been traumatised by what they themselves did to others, you run the risk of being seen to be exculpating them, excusing their crimes, absolving them of responsibility, effectively turning them into victims. I don't think this is necessarily the case, but that conflation is deeply entrenched. And yet it is crucial to disentangle the two concepts, because there is a tendency in trauma studies to over-identify with victimhood, which leaves people blissfully unaware of their own complicity in traumatic abuses or their own potential for evil. It's very reassuring and comforting always to identify with innocent victims, as it confirms us in our belief that we're on the side of the angels. However, this risks rendering the figure of the perpetrator unknowable and prevents us from recognising ourselves in them. Theorists who have begun to explore the perpetrator experience lately-or the experience of various in-between groups or their descendants-include Joshua Pederson, Alan Gibbs, Sue Vice, and Michael Rothberg. I think this is vitally important work.

I've recently also come across two fascinating books about 'future-tense trauma' or 'pre-traumatic stress disorder'. Ann Kaplan and Paul SaintAmour use these terms in their respective books Climate Trauma and Tense Future, which both came out in 2015 (Kaplan, 2015; Saint-Amour, 2015). They seem to have arrived independently at pretty much the same idea, without being aware of each other's work. Saint-Amour writes about how, in the interwar period, the prospect of a second world war that would be even more devastating than the first one haunted cultural production and had a very real psychological impact on modernist writers and artists. Kaplan studies literature and films about climate change, which is also the direction in which my own research is moving. Much climate fiction deals with very unsettling events and experiences, but these tend to be situated in the future. So it's not bad things that happened in the past that are having a traumatising effect in the present, which is how we usually think about trauma, but it's the anxious anticipation of a future catastrophe that is having such an impact. I'm not entirely sure I buy these notions of pre-trauma, pre-traumatic stress syndrome, future-tense trauma, or whatever you want to call it, but I'm intrigued by them, and I do think there is potential for more work along these lines.

MRL: Maybe I can be a bit provocative here. You said trauma studies is moving beyond Eurocentric frameworks, beyond a certain trauma aesthetics, beyond the victim-perpetrator divide. I sometimes wonder to what extent we might have to move beyond the concept of trauma as such, especially when we look at-as you did in your lecture here at Warwick University-large-scale effects of violence such as globalised 
webs of exploitation or violence that takes place in huge temporal frameworks. How useful is the concept of trauma?

SC: I share your concern about the over-use of the term 'trauma' -in fact, I suspect that the notion of pre-traumatic stress disorder is a good example of that; hence also my reservations about it. I've been active in trauma studies for quite a while now, but I certainly don't see my role as promoting the random use of this term-quite the contrary even. I often get very uncomfortable when people apply it very loosely, to all sorts of phenomena that are far removed from the more clinical understanding of the concept. I think this eagerness to see trauma everywhere is due in part to an apparent tendency to believe that something is wrong and needs to be fixed only if it has a traumatising impact. In reality, though, there are many forms of injustice that are not necessarily traumatising, or whose traumatising impact is only a small part of the story, but which need to be addressed anyway. As Michael Rothberg argues in his preface to the collection The Future of Trauma Theory, it is questionable whether viewing complex issues such as exploitation in an age of globalised neoliberal capitalism or the devastations caused by human-induced climate change exclusively through the lens of trauma really helps us understand them better, let alone tackle them effectively (Rothberg, 2013). Trauma studies is but one mode of enquiry among others; it cannot and must not displace other approaches and methodologies. So I'm all for recognising limits to its usefulness and legitimacy.

\section{Memory Studies: State of the Field}

MRL: What is your understanding of memory studies, and what is the current state of the field?

SC: That's a big question! Memory emerged as an urgent topic of debate in the humanities and the social sciences in the 1980s. That's when it became a key concept and a specific context of interdisciplinary research. The last few decades have seen a profusion of important work on memory, leading some to speak of a 'memory boom'. I think it's fair to say that memory studies has consolidated into a thriving academic field by now. Just think of the ever-growing number of research centres, funded projects, and networks devoted to memory, the many specialist journals and book series that have been established, the various attempts that are being made to provide overviews of the state of the art in this field, and the numerous new university courses and programmes that deal with memory. The recent foundation of the Memory Studies Association (MSA) takes this process of institutionalisation even further. So I would say the field is very healthy indeed. 
As it happens, I've just read an article on this topic by Anamaria Dutceac Segesten and Jenny Wüstenberg which concludes that memory studies is at 'a mid-level state of development' (Dutceac Segestern et al., 2017). One thing that struck me about this article is its teleological thrust. The authors seem to have in mind an end point that the field should ideally be moving towards. In their view, memory studies cannot be completely successful as an academic field until there are Master's and Ph.D. degrees in memory studies, jobs in memory studies, and memory studies departments. I'm not sure I agree that we can't really be satisfied with how things are going until-or unless-we arrive at that point where memory studies effectively becomes a discipline in its own right. I'm not sure we'll ever get there, and I'm not sure that's necessarily desirable either. Maybe that's in part because of my background in literary studies, where, at least since the advent of theory in the 1960s, it's been completely normal for scholars to borrow from all sorts of other disciplines, most prominently philosophy, psychology, history, and sociology. In fact, these kinds of interdisciplinary cross-fertilisations have led to some of the most exciting work in literary studies out there. I feel quite comfortable being a literary scholar as well as a memory scholar, so personally I'm not convinced there's much to be gained from getting to a stage where people self-identify as memory scholars only, at the exclusion of other professional identities.

Rebekah Vince: What are the differences between transcultural and transnational memory? Where do you think they fall short, and to what extent are they in dialogue with one another?

SC: Some scholars seem to prefer the one term, others the other. They're often used interchangeably, though-in fact, I've been guilty of that myself. However, I think it's worth pointing out that they're not actually synonymous. Within a single nation-state, for example, there can be different cultures, so there is such a thing as transcultural memory that is not necessarily transnational. Conversely, transnational phenomena are not always transcultural-think of the global reach of Hollywood films, for example. I'm under the impression that memory scholars who favour the term 'transnational' generally have a background in the social sciences and are concerned with the obstacles that prevent memory from circulating freely across boundaries. By contrast, people who prefer the term 'transcultural' tend to have a literary or cultural studies background and focus primarily on processes of border-crossing without paying as much attention to such impediments. This is perhaps in part because cultural boundaries tend to be less concrete and solid, more fluid and ephemeral, than boundaries between nation-states. So to some extent, at least, it seems to me to be a matter of different disciplinary affiliations and different emphases. 
In my own work in this area, I have tended to dwell on the risks involved in remembering across cultural or national boundaries, in part because there are so many proponents of the transcultural or transnational turn in memory studies who seem to take for granted its beneficial effects, or at least to foreground these while overlooking or minimising more troubling manifestations of transcultural or transnational memory. The work of Daniel Levy and Natan Sznaider, Jeffrey Alexander, and Alison Landsberg comes to mind, as well as that of Cathy Caruth. Each in their own way, these theorists tend to highlight the cathartic, healing, emancipatory, prosocial potential of transcultural or transnational remembrance. I think that's an interesting idea that's definitely worth entertaining, but I would add that a healthy dose of scepticism is called for, as it clearly doesn't always work that way.

\section{The Ethics and Politics of Memory (Studies)}

$R V$ : Do you see a political turn in memory studies? What can memory studies bring to political debates and what are the dangers? In what way is memory instrumentalised?

SC: In our present moment, I think memory studies definitely has a contribution to make to the ongoing debate over Confederate monuments and how to memorialise the Civil War in the US post-Charlottesville, as well as to similar debates elsewhere. There is a lot of soul-searching going on right now in many different places around the world about the ethics and politics of historical commemoration - the 'Rhodes Must Fall' campaigns in Cape Town and Oxford are another recent example. Just clarifying the terms of such debates would already be enormously helpful, it seems to me. It bothers me, for example, listening to advocates of leaving Confederate flags or statues of Confederate generals or British colonialists in place, to hear protestors being accused of trying to 'erase history', while what they're actually doing is opposing the glorification of hateful symbols and dubious historical figures, which is something completely different. By injecting some much-needed conceptual hygiene and adding context and nuance, memory studies can help raise the level of debates about how to handle controversial monuments and memorials.

I think it's important to stop thinking in simplistic terms about the ethics and politics of memory. There is a strong tendency to assume that remembering is inherently good and forgetting inherently bad. This popular notion underlies the 'never again' imperative of Holocaust remembrance, or the 'no more war' slogan inscribed on the Yser Tower, a famous First World War memorial in Flanders. The belief is that remembering will save us from repeating the horrors of the past; if we forget them, though, we are doomed to do just that. In reality, however, the situation is a lot murkier and less clear-cut. The distinction between 
remembering and forgetting doesn't map neatly onto that between good and evil.

I'm sure we can all easily think of instances where remembering a painful history has not had a very salutary effect. To stay with the example of the Holocaust, the memory of the Nazi genocide of the European Jews is often invoked for immoral purposes. Think of George W. Bush using Nazi comparisons to rally support for his illegal pre-emptive war against Iraq in 2003. Bush compared Saddam to Hitler, and suggested that his gas attacks on the Kurds and Iranians during the Iran-Iraq war amounted to a holocaust. Or take the case of Israel, the society where the Holocaust is at the very centre of collective memory. Israel has frequently used the memory of the Holocaust to legitimise extreme violence against the Palestinians and neighbouring Arab countries. Visions of a 'second Holocaust' allegedly facing the Jewish people from the Palestinians resisting the occupation or from Arab states in the region have repeatedly been invoked by Zionists as part of a strategy to justify whatever Israel does as self-defence. Another example of collective memory producing further bloodshed instead of justice is that of the Yugoslav wars of the 1990s, where Serb leaders justified killing Bosniaks and Kosovars by conjuring up memories of the 1453 Fall of Constantinople and the 1389 Battle of Kosovo that fomented ancient hatreds.

Conversely, forgetting isn't inevitably harmful but can in fact be beneficial, as the journalist David Rieff has recently argued in his provocative book In Praise of Forgetting (Rieff, 2016). Memory scholars like Paul Connerton and Aleida Assmann have also taken issue with the tendency to see forgetting as this monolithic evil thing (Connerton, 2008; Assmann, 2014). They point out that there are different forms of forgetting, some destructive, others constructive. As an example of the latter, Assmann mentions Winston Churchill's plea for oblivion as a necessary condition for laying the foundations of a new Europe. Addressing a student audience in Zurich in 1946, Churchill said that in order for Europe to come together and begin anew after the devastations of the Second World War, it would have to forget the hatreds, crimes, and injuries of the past. The past's hold on the present had to be broken for Europe to be able to make a fresh start.

So while I welcome the increased attention given to the ethics and politics of memory, I think we need to question simplistic models where remembering is automatically seen as the ethical option and forgetting as what is to be avoided at all costs. In reality, things are a lot messier, a lot less straightforward, and you can't really make abstraction of the specific contexts in which remembering or forgetting takes place. I think it's 
important for memory studies as a field to bring clarity, nuance, and historical depth to debates over such issues.

Something that got me thinking about all of this is the coincidence of the refugee crisis and the centenary of the First World War, which is being commemorated very intensely in Flanders, where I live. You could argue, though, that the war is simultaneously being forgotten very actively and successfully. You've got leading politicians in the province of West Flanders, which saw some of the worst fighting of the First World War, attending commemorative ceremonies one day, in which they speak lofty words about peace and about honouring victims, only to fulminate against refugees knocking on our door the next day, people fleeing war in Syria or Iraq in the present. There seems to be a disconnect, a form of cognitive dissonance, which led me to question the value and function of these commemorative events. In these ceremonies we profess to hold dear certain timeless values, which supposedly guide our behaviour, but that turns out not to be the case at all. There's a glaring contrast between our words about lessons learnt from history and all that, on the one hand, and our actions in the present, on the other. Historical commemorations seem to have become hollow rituals inducing moral complacency and selfcongratulation. This made me wonder whether as memory scholars we're somehow complicit in this state of affairs, despite our best intentions; whether we may inadvertently be facilitating or legitimising this kind of empty virtue signalling; and, if so, what, if anything, is to be done about that.

$M R L$ : I find that interesting because, for example in the case of Germany, Holocaust memory and the culture of Holocaust commemoration have led to a very different debate around the refugees, not to say that it has been led in an exemplary way throughout. The question that is implied in what you said is what makes certain constellations work and certain constellations not work? How can we ensure that we have this dialogic form of memory instead of one that closes down? Maybe that's where our responsibilities come in as memory scholars.

SC: Absolutely. Obviously, other factors are at play as well, including economic ones, but I think you're right: the memory of the Holocaust in Germany definitely informs the more welcoming reception that refugees have been given there compared to most other European countries. In Germany, which is often held up as a shining example of a country that is facing up to a difficult past, commemorative activity would appear to have had a more pro-social effect than has been the case in many other countries, including Belgium. It's as if extending hospitality to refugees is a way of atoning for the Holocaust. Then again, let's not forget the remarkable success of the far-right party Alternative für Deutschland in 
the recent German parliamentary elections, which was fuelled in no small part by anti-immigrant, racist sentiments. In other words, the German case is complicated too.

$R V$ : Can you talk more about the Belgian context in terms of memory wars and multidirectional memory?

SC: I'm an English literature scholar, so most of my research has tended to focus on the English-speaking world. Consequently, I haven't done much work on memory in Belgium, though I obviously take an interest in it. As my brief discussion of First World War commemoration just now indicated, I think there is a bit of a problem with multidirectionality in Belgian memory culture, in the sense that I don't see much evidence of forms of solidarity being achieved through the interaction of memories of different histories. I'm actually under the impression that the Holocaust, in particular, serves as something of a screen memory in Belgium, hiding from view the country's shameful colonial history, which we're still nowhere near coming to terms with. Until quite recently, the Royal Museum for Central Africa in Tervuren, just outside Brussels, was known as the last unrepentant colonial museum in Europe, and for good reason. There are numerous statues of and streets named after King Leopold II throughout Belgium, while Patrice Lumumba is completely absent from public space, unlike in many other countries. Five years ago a high-profile Holocaust and Human Rights Museum opened in Mechelen, next to the site of the former transit camp from which Belgian Jews were deported during the Second World War. As its name suggests, the museum devotes attention not only to the Holocaust but also to other human-rights violations. However, it all but ignores the elephant in the room: the colonial atrocities in the Congo Free State, which Adam Hochschild and others have called 'the African Holocaust'.

Speaking of Hochschild, I still vividly remember the shock I felt upon reading King Leopold's Ghost when I was in my twenties, as I hadn't learnt anything about that darkest chapter of Belgian history in school-an experience that, I'm sorry to say, is widely shared by Belgian schoolchildren to this day (Hochschild, 1998). That's why, whenever I teach Joseph Conrad's Heart of Darkness to my students, I make a point of discussing the novella's historical context at some length. As director of the Cultural Memory Studies Initiative at Ghent, I also try to stimulate reflection on the legacies of our colonial history by giving a platform to people doing work that speaks to these issues. I'm thinking, for example, of a lecture we organised on 19th October 2017 in which an American art historian discussed 'the great forgetting' of Belgium's exploitation of Congo and showed how some of our most cherished cultural traditions are implicated in colonial violence, or of an interview we put on a couple of 
years ago with the author of a children's book that challenges the Zwarte Piet stereotype, which is a colonial hangover.

$R V$ : To what extent are the decisions you make as a memory studies scholar political? What is the political responsibility of the memory studies scholar, if there is one?

SC: I'm wary of making grandiose claims for the relevance and utility of our work. However, I do think memory and trauma scholars can, and maybe should, try to intervene in the pressing matters of the day, perhaps now more than ever. After all, the dire political situation we are in at the moment lends a sense of urgency to the calls for memory and trauma studies to become more future-oriented instead of merely backwardlooking that have frequently been issued in recent years. Speaking for myself, I think a concern with ethics and politics is at the heart of much of my research on issues of trauma and memory. Take, for example, my book Postcolonial Witnessing. In a nutshell, the argument I make there is that trauma studies, for all the lip-service it pays to the promotion of crosscultural solidarity, actually falls short in that regard, as it's marked by a Eurocentric, monocultural bias. Despite the omnipresence of violence and suffering in the world, most attention within classical or canonical trauma studies has been devoted to events that took place in Europe or the US, primarily the Holocaust and 9/11. The founding texts of the field marginalise or ignore the traumas suffered by members of non-Western and minority groups, such as racism, slavery, and colonialism. As a result, they risk perpetuating the very beliefs and structures that underlie existing inequalities and injustices instead of challenging them. I contend that, for trauma studies to realise its self-proclaimed ethical potential, it will among other things have to broaden its focus to encompass the suffering inflicted on non-Western and minority populations, and to revise and expand existing definitions of trauma and recovery that have developed out of the history of Western modernity. Again, I don't wish to overstate the book's likely impact, but I do believe that making these kinds of arguments amounts to a potentially worthwhile ethical or political intervention, not least also in the light of the global refugee crisis and the heartless response to it that we've been seeing in many parts of the world.

\section{The Future of Memory Studies}

MRL: Looking ahead, what would you identify as the most important and biggest trends in memory studies at the moment?

SC: Let me perhaps start by saying that I find it somewhat ironic that as memory scholars we are so obsessed with the future of our field. It's a question that comes up at pretty much every conference I attend or roundtable in which I participate: what is going to be the next big thing? 
Memory studies is supposedly concerned with holding on to the past, yet it seems as if we are constantly trying to 'make it new', to coin yet another fancy concept to render obsolete and supersede the last one. To a large extent, of course, this insatiable hunger for novelty is driven by economic factors, such as the demands of the academic publishing industry and the tenure and promotion system. Books and articles that promise to revolutionise or transform a field are more likely to get published, get cited, and lead to career advancement than those making more modest claims. So I understand where the urge comes from, yet I can't help wondering whether it wouldn't be better if memory studies, of all fields, slowed down a little and took the trouble to look backwards and use existing theories, methodologies, and concepts to their full potential instead of frantically pursuing innovation.

Having said that, though, I'm happy, of course, to talk about what I see as some significant new developments. As I suggested in my talk for the Memory Group here at Warwick University, I think the notion of the Anthropocene, the idea that we have entered a new geological epoch defined by the actions of human beings, poses interesting challenges for memory studies, with which the field is only just beginning to grapple in earnest. I recently published a roundtable on this topic, which brought together the position papers presented in a panel that I chaired at the MLA convention in Philadelphia in January 2017 (Craps et al., 2018). It seems to me that there is a shift underway in the field from the transnational, transcultural, or global to the planetary, from recorded to deep history, and from the human to the non-human. There is a sense in which the gradual scalar expansion that underlies the previous phases of memory studies, identified by Astrid Erll in her influential essay on travelling memory from 2011 (Erll, 2011), is being taken to another level-I call it 'travelling memory on steroids'-while the humanist assumptions undergirding these phases are also being called into question. In order for memory studies to start thinking ecologically rather than merely socially, it may need to break with anthropocentric modes of cognition and representation. In the years ahead, I expect to see a lot more work on how the magnitude of our environmental predicament is affecting the objects, the scales, and indeed the very nature of memory.

The study of digital memory is another prominent trend. There have been some important books published about this recently, including Andrew Hoskins's edited collection Digital Memory Studies (Hoskins, 2017). A couple of years ago, Hoskins co-edited another seminal book, Save as... Digital Memories, with Joanne Garde-Hansen and Anna Reading (GardeHansen et al., 2009). However, I think there is a need for more research on the impact of the digital revolution on the production, circulation, preservation, and transmission of memories. I've been struck by 
contemporary anxieties about digital memory, which sometimes seem quite contradictory to me. It's as if they go in opposite directions, which largely correspond to two different time frames. Much has been written about how our collective memory is expanding at an astonishing rate as a result of the rise of digital technology, leading to fears that our internal, individual memories are shrinking (because we increasingly outsource our memory to the web) as well as to calls to adopt legislation that would enshrine a 'right to be forgotten' (because the internet remembers everything, and hence photos and posts to social networking sites can return to haunt us when prospective employers, for example, have access to them). It seems to me that these anxieties are animated by a very presentist perspective; if you take a longer view-decades instead of years, centuries instead of decades - the problem we face is not so much how to cope with the abundance of memory as how to handle its fragility. By focusing on the proliferation of information in the digital age, we tend to overlook the instability and transience of this information. Our current media technologies privilege transmissibility over durability, much more so than the technologies that we used in the past, such as clay tablets, scrolls, and paper. As formats change, software is retired, and hardware becomes obsolete, information stored on computers can easily become inaccessible. Unless we begin to take digital preservation more seriously, there is a real risk that the twenty-first century will come to seem like what the internet pioneer Vint Cerf has recently called a 'digital Dark Age'. Whether we can trust commercial enterprises such as Google and Facebook, which manage much of our digital information for us, as guardians of digital memory is an open question. Frankly, I'm not too optimistic, as ensuring the long-term protection of our data runs counter to their short-term economic interests. Publicly funded, not-for-profit institutions such as libraries and archives are probably our best hope, but they will need far more resources to be able to cope with the data deluge that the digital revolution has unleashed, which will also involve developing filtering mechanisms and protocols to determine what data needs to be saved and what can be discarded.

MRL: What are the challenges for the future of memory studies?

SC: I'd say the main ones are probably interdisciplinarity and internationalisation. Interdisciplinarity is something everybody champions, but in reality it is quite rare. Memory studies is a multidisciplinary field, but I would hesitate to call it a genuinely interdisciplinary one. The challenge is how to get people from different walks of life to actually collaborate and exchange in a real sense. I'm thinking not only of people with different disciplinary backgrounds, but also of academics and practitioners, or of academics and policy-makers. Another challenge is how to internationalise memory studies in a 
meaningful way beyond Europe and North America. There is a lot of talk about transnational, global, and planetary memory, but all too often we're actually just having a provincial conversation among like-minded Westerners; it rarely goes beyond that. We should really do something about that, though that's easier said than done, of course. After all, there is no quick fix for the inequalities in the world that account for the marginal role that perspectives of memory scholars from the Global South have tended to play. However, I have good hope that the MSA will help us confront both of these challenges, of which the association is well aware, in the years to come.

\section{References}

Assmann, A. (2014), 'Forms of Forgetting', public lecture held at Castrum Peregrini in Amsterdam on 1 October 2014 on being awarded the 2014 Dr A. H. Heineken Prize for History. http://castrumperegrini.org/2014/10/30/forms-of-forgetting/, (Accessed: 2nd January 2018).

Connerton, P. (2008), 'Seven Types of Forgetting'. Memory Studies, 1 (1), 59-71.

Craps, S. (2013), Postcolonial Witnessing: Trauma Out of Bounds. Basingstoke: Palgrave Macmillan.

Craps, S., R. Crownshaw, J. Wenzel, R. Kennedy, C. Colebrook, and V. Nardizzi (2018), 'Memory Studies and the Anthropocene: A Roundtable'. Memory Studies, 11 (4), forthcoming. Published via OnlineFirst on 10 October 2017. DOI: 10.1177/1750698017731068.

Dutceac Segesten, A. and J. Wüstenberg (2017), 'Memory Studies: The State of an Emergent Field'. Memory Studies, 10 (4), 474-489.

Erll, A. (2011), 'Travelling Memory'. Parallax, 17 (4), 4-18.

Garde-Hansen, J., A. Hoskins and A. Reading (eds.) (2009), Save as...

Digital Memories. Basingstoke: Palgrave Macmillan.

Gibbs, A. (2014), Contemporary American Trauma Narratives. Edinburgh: Edinburgh University Press.

Hochschild, A. (1998), King Leopold's Ghost: A Story of Greed, Terror, and Heroism in Colonial Africa. Boston: Houghton Mifflin.

Hoskins, A. (ed.) (2017), Digital Memory Studies: Media Pasts in Transition. London: Routledge. 
Kaplan, E. A. (2015), Climate Trauma: Foreseeing the Future in Dystopian Film and Fiction. New Brunswick: Rutgers University Press.

Luckhurst, R. (2008), The Trauma Question. London: Routledge.

Rieff, D. (2016), In Praise of Forgetting: Historical Memory and Its Ironies. New Haven: Yale University Press.

Rothberg, M. (2013), 'Beyond Tancred and Clorinda: Trauma Studies for Implicated Subjects', in G. Buelens, S. Durrant and R. Eaglestone (eds.), The Future of Trauma Theory: Contemporary Literary and Cultural Criticism. London: Routledge, pp. xi-xviii.

Saint-Amour, P. K. (2015), Tense Future: Modernism, Total War, Encyclopedic Form. Oxford: Oxford University Press.

To cite this article:

Roca Lizarazu, M., and Vince, R., (2018). Memory Studies Goes Planetary: An Interview with Stef Craps. Exchanges: The Interdisciplinary Research Journal, 5(2), 1-15. Retrieved from:

http://exchanges.warwick.ac.uk/index.php/exchanges/article/view/245 